\title{
Food beliefs and practices during pregnancy in Northern Ghana: Implications for nutrition counseling
}

\author{
Abdulai Abubakari'1,2, Albrecht Jahn², Claudia Beiersmann² \\ ${ }^{1}$ Community Nutrition Department, School of Allied Health Sciences, University for Development Studies Tamale, Ghana \\ ${ }^{2}$ Medical Faculty, Institute of Public Health, University of Heidelberg, Germany
}

\begin{abstract}
Cultural practices and beliefs are important factors that could influence a woman's dietary choices during pregnancy. We investigated food beliefs among pregnant women in Northern Ghana. In-depth interviews were conducted with thirty women, selected from three districts. We describe food beliefs regarding 'recommended' and 'prohibited' foods during pregnancy. There was a general agreement among participants about the recommended foods but not on the prohibited foods. For example, for some banana was regarded as prohibited, while for others it was recommended. Hypersensitivity to smell was attributed to nausea, vomiting and spiting and was largely the most important factor that could modify dietary habits of those who experienced it. Pregnancy is a sensitive phase and thus requires critical care and attention. Therefore, individualized counseling during antenatal clinics instead of the ongoing mass education is recommended as this will help address conditions peculiar to individual pregnancies.
\end{abstract}

Key Words Northern Ghana, beliefs, food, knowledge, pregnancy, qualitative

\section{BACKGROUND}

Optimal nutrition throughout the life course ensures good health and long life. It is a fundamental cornerstone of any individual's health. This is especially important for women, as inadequate nutrition has negative consequences not only on women's own health but also on the health of their children. ${ }^{1,2}$.

Changes in lifestyle, diet, urbanization, and reduced physical activity contribute to the double burden of disease in developing countries. Regarding nutrition, under-nutrition (lack of proper nutrition, caused by not having enough food or not eating enough food containing substances necessary for growth and health) coexists with over-nutrition $3,4,5$ (Overconsumption of certain nutrients, such as protein, calories or fat). In Ghana, women of childbearing age experience malnutrition in two ways: poor women mostly experience under nutrition while wealthier women experience over nutrition ${ }^{6}$. Under nutrition leads to underweight while overnutrition leads to overweight/obesity. Underweight and overweight/obesity are both forms of malnutrition. Both conditions during pregnancy could have adverse consequences on the mother as well as infant later in life. For example, overweight and obese women are more likely to experience gestational diabetes and hypertension, which undermine their physical and psychological well-being during pregnancy and increase their chance of delivering macrosomic babies (babies born with a birth weight $\geq 4 \mathrm{~kg}$ ), who may also develop obesity and diabetes later in life. ${ }^{7}$ Women at the community level may not have sufficient knowledge on maternal nutrition. Recent interventions in

(C) 2019 Abdulai Abubakari, Albrecht Jahn, Claudia Beiersmann. This is an open access article distributed under the terms of the Creative Commons Attribution License (CC-BY 4.0), which permits the user to copy, distribute, and transmit the work provided that the original author(s) and source are credited.

Send correspondence to: abubakari.abdulai1@uds.edu.gh 
Ghana to improve pregnancy outcome (successfully delivery of normal baby without complication) have had mixed success: women have not fully adopted the practice of taking daily micronutrient supplements although they understand their benefits. Similarly, compliance with antenatal micronutrient supplement intake such as vitamin A, iron and folic acid and dietary advice across the country is low. ${ }^{8}$ Therefore experts demand the development of more effective nutrition interventions in order to ensure optimal maternal and infant nutrition., 910

The health of the people is reflected by what they eat. Nevertheless, many people select foods for reasons other than their nutritional values. People may abstain from certain foods and beverages because of religious or cultural reasons. Such food taboos may for example forbid the meat of a particular animal, including mammals, rodents, reptiles, amphibians, bony fish, molluscs and crustaceans. ${ }^{11}$ Religious and cultural beliefs and perceptions also influence maternal eating patterns during pregnancy. ${ }^{12}$ For example a recent study from Nigeria reported common food taboos among pregnant women: eating snails or okra during pregnancy would make the baby drool saliva, eating bush animals would inflict evil spirit on the pregnant woman resulting in delivery of a monster; and drinking cocoa containing beverages would make the baby very big and difficult to deliver. ${ }^{13}$ Eating yam or "foofoo" (a staple food made of cassava and green plantain flour) was believed to make the baby big and difficult to deliver, while eating pork meat would make the baby spotted at birth. ${ }^{14}$ Also in some cultures in Ghana, pregnant women are expected to avoid certain foods out of fear and belief that these could harm the unborn child. ${ }^{15}$ Often, traditional practices and religious beliefs influence pregnant women, probably because these practices and beliefs are said to be time-tested methods, which have been successfully used by generations of family and friends. However, it might happen that due to these practices, pregnant and lactating women in various parts of the world abstain from especially nutritious and beneficial foods. $16,17,18,19$

At the health centers and hospitals in Ghana pregnant women are usually given nutrition education and counseling during antenatal care (ANC) visits, which has implications on maternal and child health. The counseling during ANC visits derives from the belief that indigenous nutrition knowledge is insufficient compared to an expert's nutrition knowledge. However, it is found that the expert status of scientists and their specific common sense ('expert knowledge') is not always better than that of the non-expert or non-scientist's common sense (indigenous knowledge). ${ }^{20,21}$ Furthermore, by ignoring the indigenous knowledge, researchers and health service providers fail to incorporate the complex range of beliefs, knowledge, and practices that shapes women's pregnancy experiences and food practices and this limits their efforts to providing effective counseling and nutrition interventions during pregnancy.

The causes of malnutrition are complex. Religious and cultural beliefs influencing dietary practices are an important factor influencing the nutritional status of a population. Intervention programs need to address these factors. The aim of this study is to investigate food beliefs among pregnant women in Northern Ghana and its implications on nutrition counseling during pregnancy.

\section{METHODOLOGY}

The study used a qualitative approach, using individual in-depth interviews as data collection tool.

\section{Study Area}

The study took place in the Northern region, which is one of the ten regions of Ghana. The region is among the poorest regions in the country and the main occupation of the people is agriculture and related activities. The Northern region has 26 districts, with 24 of them being predominantly rural. ${ }^{23}$ The most urbanized city in the region is Tamale Metropolis which represents about half the population in size. Illiteracy rate in the region is $62.8 \% .^{23}$

\section{Study Population and Sampling}

Three districts were purposively selected to reflect rural and urban areas. The districts Tamale Metropolis and Sagnarigu District represent the urban area. The latter was hitherto part of the Tamale Metropolis and today still draws health services from Tamale Metropolis. The Savelugu-Nanton Municipality represents the rural area. In total, thirty mothers (with babies 0-1 month old) were purposively (based on educational status, ethnicity etc.) selected to participate in the in-depth interviews. The sample aimed at a diversity of the participants' background (heterogeneous sampling). ${ }^{24}$ Twenty mothers were selected from three hospitals in the Tamale Metropolis/Sagnarigu 
District, representing the urban area: ten mothers were selected from the Tamale Teaching Hospital (TTH) (the biggest referral facility in Northern Ghana) and five each from the Tamale Central (TCH) and West Hospitals (TWH). Ten mothers were selected from the Savelugu-Nantong Municipal Hospital (SDH), representing the rural area. A detailed illustration of the sampling procedures can be seen in Figure 1.

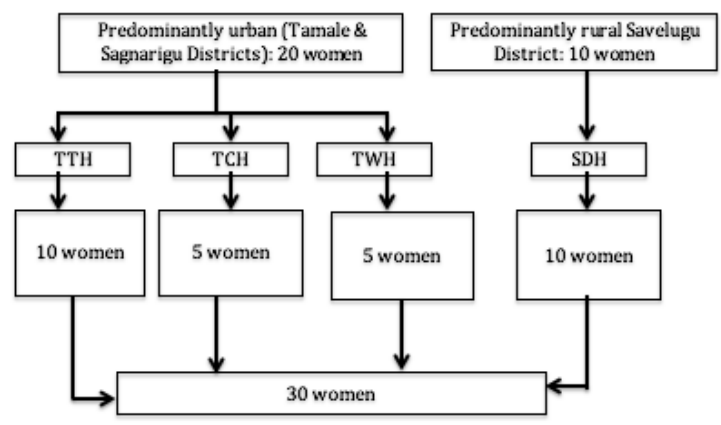

Figure 1. Sampling Procedures

\section{Data Collection Procedures}

The research was conducted to obtain an in-depth understanding on the factors that influence maternal dietary habits and food intake during pregnancy. The in-depth interviews were conducted to gain information on the recommended and prohibited pregnancy foods, including sources of knowledge and functions of the foods. The questions centred on the following:

$>$ Recommended and prohibited foods during pregnancy (creation of a list of recommended and prohibited foods)

$>$ Why a particular food was consumed or not consumed during pregnancy?

$>$ Sources of knowledge of food and their functions

$>$ Factors mediating food practices during pregnancy.

The interviews were conducted at the health facilities (Hospitals) where the women were drawing antenatal and postnatal services. Research assistants conducted tape-recorded interviews in the most dominant language (Dagbani) spoken in the North. Additionally, notes were taken for backup purposes and in order to ensure completeness of records. The saturation point was reached after the $26^{\text {th }}$ interview, as the remaining four interviews did not provide varied responses.

\section{Data Analysis}

The analysis was done using computer assisted qualitative data analysis software NVivo (version 10) (QSR international Pty Ltd, Doncaster, Victoria, Australia).

The field notes and audio recordings were translated, and a thematic analysis was performed. The analysis started by reading, coding, and then categorizing the qualitative transcripts. Coding nodes were generated based on the study objectives and the main themes of the interview guide. Specifically, the coding was done by finding references to different ideas, concepts or categories in the form of sentences, phrases and paragraphs within the sources (transcript), which represented them. When a meaningful segment of the text was found a code was assigned or category named to signify that particular segment. This continued until all the text was segmented. The process was repeated several times to make sure that all the relevant segments important to the study objectives were identified and coded.

Queries were used to find document content coded by a specific combination of nodes, or combination of nodes and attributes. They were made purposefully to identify content in the transcript with particular text so that they could be used as a basis for further analysis. The detailed coding tree is given in Figure 2. 
Abubakari, Jahn, Beiersmann

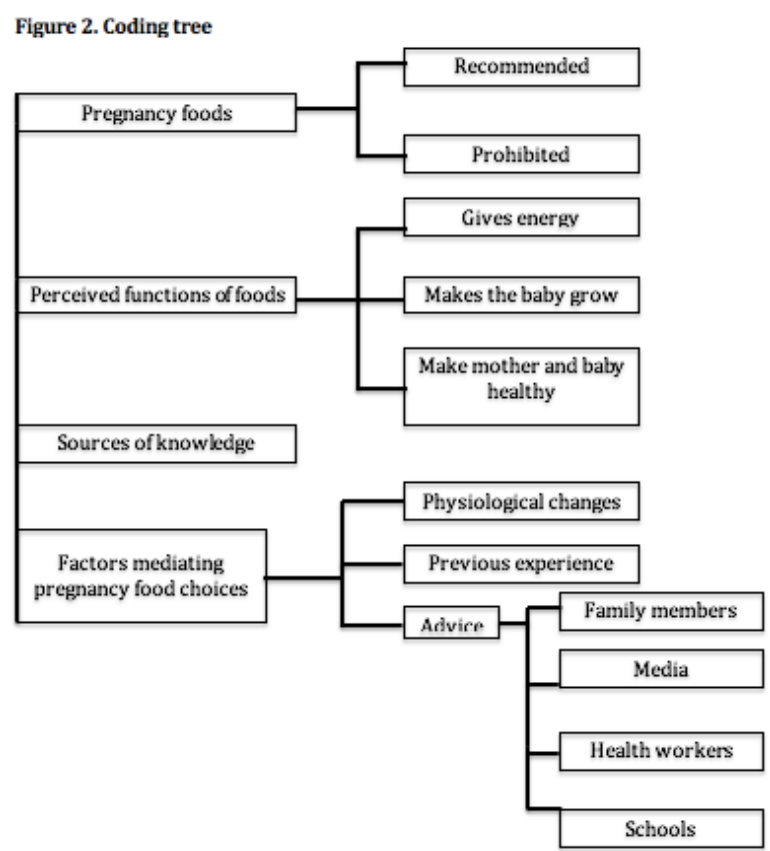




\section{RESULTS}

Results are presented based on two key areas. The first part focuses on the respondents recommended and prohibited foods during pregnancy and sources of knowledge. The second part illustrates the respondent's perspectives of the functions of the foods. Crosscutting themes include factors influencing pregnant women's food choices/practices and the extent to which this enhances or undermines compliance to nutrition counseling during antenatal services.

The majority ( $50 \%$ ) of respondents were between the age ranges of $20-30$ years old. With regards to ethnicity Dagomba, the dominant ethnic group in the North of Ghana, was the majority (33\%), 20.0\% of respondents were Gonja, 17.0\% were Mampurisi, 13.0\% were Kokomba and the rest were other ethnic groups such as Fulani, Moosi, Farafara, Hausza and Ashanti. About one third of the mothers $(33.0 \%)$ had no education, $30 \%$ had primary education, $23.0 \%$ had secondary education and $13.0 \%$ had tertiary education. The majority of respondents $(33.0 \%)$ were housewives. About two thirds of the respondents were Muslims. More than half of the mothers $(60 \%)$ were urban dwellers while $40.0 \%$ were rural dwellers. With regards to occupation majority $(33 \%)$ of the respondents were housewives while $23 \%$ were traders. The rest were engaged farming $(13 \%)$ hair dressing $(10 \%)$, seamtress (6.7\%) and teaching (13.3\%) (Table 1$)$.

\begin{tabular}{|c|c|c|}
\hline Variables & Categories & $\mathrm{n} / \mathrm{N}(\%)$ \\
\hline \multirow{3}{*}{$\begin{array}{ll}\text { Age } & \text { of } \\
\text { mothers } & \\
\text { (years) } & \end{array}$} & $<20$ & $5 / 30(16.67 \%)$ \\
\hline & $20-30$ & $15 / 30(50.0 \%)$ \\
\hline & $>30$ & $10 / 30(33.33 \%)$ \\
\hline \multirow[t]{5}{*}{ Ethnicity } & Dagomba & $10 / 30(33.33 \%)$ \\
\hline & Gonia & $6 / 30(20.0 \%)$ \\
\hline & Mampurisi & $5 / 30(16.67 \%)$ \\
\hline & Kokomba & $4 / 30(13.33 \%)$ \\
\hline & Other ethnic groups & $5 / 30(16.67 \%)$ \\
\hline \multirow[t]{4}{*}{ Education } & No education & $10 / 30(33.33 \%)$ \\
\hline & Primary & $9 / 30(30.0 \%)$ \\
\hline & Secondary & $7 / 30(23.33 \%)$ \\
\hline & Tertiary & $4 / 30(13.33 \%)$ \\
\hline \multirow[t]{6}{*}{ Occupation } & Traders (Market, store, hawker) & $7 / 30(23.33 \%)$ \\
\hline & Farmers & $4 / 30(13.33 \%)$ \\
\hline & Housewife & $10 / 30(33.33 \%)$ \\
\hline & Hairdresser & $3 / 30(10.0)$ \\
\hline & Seamstress & $2 / 30(6.67 \%)$ \\
\hline & Professional (Teacher, Nurse, Banker, Secretarial) & $4 / 30(13.33 \%)$ \\
\hline \multirow[t]{2}{*}{ Religion } & Muslims & $22 / 30(73.33 \%)$ \\
\hline & Christians & $8 / 30(26.67 \%)$ \\
\hline \multirow[t]{2}{*}{ Residence } & Urban & $18 / 30(60.0 \%)$ \\
\hline & Rural & $12 / 30(40.0 \%)$ \\
\hline
\end{tabular}

\section{Recommended and Prohibited Foods Area}

The women generated a wide range of recommended foods. Food lists were generated and categorized into (1) recommended food list and (2) prohibited food list (see Table 2). Most of these foods are indigenous/traditional Ghanaian staples (e.g. green leafy vegetables, legumes, cereals, roots and tubers, nuts, meat, fish, and fruits). It also included local drinks such as puba beer (a local drink made from tamarind fruits), ice kenkey (prepared from fermented corn dough and mashed) and cow milk. The list also included foreign foods such as beverages (tea, Milo), dairy products (yogurt), and biscuits (digestives, cream crackers). The content of the food list was similar across different age groups. 
Abubakari, Jahn, Beiersmann

\begin{tabular}{|c|c|}
\hline Recommended foods for pregnant women & Prohibited foods \\
\hline \multicolumn{2}{|l|}{ Cooked foods } \\
\hline Gapd (local dish made from cassava) and beans with palm oil & Banana \\
\hline Bambara beans with stew & Plantain \\
\hline Troe zaf (traditional northern staple made from corn'millet and cassava & Sugar \\
\hline flour) with soup made of dried and fresh leafy vegetables & Too much salt \\
\hline Yam with palava sauce (boiled aleefis leaves with palm oil) and & Groundnut soup \\
\hline stew & Hot pepper \\
\hline Rice with stew & Cool foods \\
\hline Yaroseres (a mixture of maize and Bambara beans boiled together) & Gazd (local dish \\
\hline Kerake (boiled fermented maize flour raped in corn husk) with hot & made from cassava) \\
\hline pepper, aleefis sauce and beans stew & Cowpea \\
\hline Fufu with palm nut, dry okra and vegetable soup & Mango \\
\hline \multicolumn{2}{|l|}{ Porridge (made of fermented millet or maize flour) } \\
\hline \multicolumn{2}{|l|}{ Bean cake (boase) } \\
\hline \multicolumn{2}{|l|}{ Ground nut paste cake (bulbuld) } \\
\hline \multicolumn{2}{|l|}{ Eggs } \\
\hline \multicolumn{2}{|l|}{ Fruits } \\
\hline \multicolumn{2}{|l|}{ Oranges } \\
\hline \multicolumn{2}{|l|}{ Mangoes } \\
\hline \multicolumn{2}{|l|}{ Watermelon } \\
\hline \multicolumn{2}{|l|}{ Banana } \\
\hline \multicolumn{2}{|l|}{ Pineapple } \\
\hline \multicolumn{2}{|l|}{ Processed foods } \\
\hline \multicolumn{2}{|l|}{ Malt } \\
\hline \multicolumn{2}{|l|}{ Honey } \\
\hline \multicolumn{2}{|l|}{ Coca-Cola } \\
\hline \multicolumn{2}{|l|}{ Ice kenke (mashed keake with sugar) } \\
\hline \multicolumn{2}{|l|}{ Babg drink (an indigenous drink made from tamarind fruit) } \\
\hline Dairy products (milk, yogurt) & \\
\hline biscuits (digestives, cream crackers) & \\
\hline
\end{tabular}

There was a general agreement among respondents about the recommended foods but not on the prohibited foods. For some women banana, mango and hot pepper were prohibited during pregnancy but were recommended by others (see Table 2). One Dagomba woman observed that consumption of banana and plantain could lead to premature contraction during pregnancy and painful child birth. Conversely, one Ashanti woman shared that banana and plantain makes her baby healthy - and thus consumes these foods frequently during pregnancy (Table 4). 


\begin{tabular}{|c|c|}
\hline Demographic characteristics of the respondent & Reasons \\
\hline \multicolumn{2}{|c|}{ Reasons associated with prohibited foods during pregnancy } \\
\hline 34-year old Dasamba waman & $\begin{array}{l}\text { "Banana and plantain cause premature } \\
\text { contraction during pregnancy and pain during } \\
\text { childbirth." }\end{array}$ \\
\hline 30-year-old Akan woman & $\begin{array}{l}\text { "Hot pepper would make my baby have skin } \\
\text { rashes and itching skin when born." }\end{array}$ \\
\hline 25-year-old Ganja woman & $\begin{array}{l}\text { "As for me when I was pregnant my mother } \\
\text { told me not to eat manga. She said that if I eat it } \\
\text { my baby will became too big and it will be } \\
\text { difficult for me to give birth." }\end{array}$ \\
\hline \multicolumn{2}{|c|}{ Perceived Functions of Food by Pregnant Women } \\
\hline 36-year-old mother of five, Gorda tribe & $\begin{array}{l}\text { "Me.... I eat Twa Zafi [traditional northern } \\
\text { staple made from corn/millet and cassava flour] } \\
\text { with green leafy vegetables when I am pregnant } \\
\text { because they give my baby and me good health" }\end{array}$ \\
\hline 25-year-old mother of two, Magusurial tribe & $\begin{array}{l}\text { "Ege, me I eat a lot of eggs, watermelon, } \\
\text { pineapple and fish with baobah soutp because I } \\
\text { hear that they give blood and make my baby } \\
\text { healthy" }\end{array}$ \\
\hline \multicolumn{2}{|c|}{ Factors Mediating Food Practices During Pregnancy } \\
\hline 32-year-old mother of five, Dasamba tribe & $\begin{array}{l}\text { "I could not eat anything with egg, fish, meat } \\
\text { or onions, and so l eat fried foods diring the first } \\
\text { three months of my pregnancy" }\end{array}$ \\
\hline 30-year-old mother of three, Hawsa woman & $\begin{array}{l}\text { "I am not able to eat anything containing } \\
\text { meat, fish or egg because I vomit after taken such } \\
\text { foods so I take only drinks and dry foodsfried } \\
\text { yam" }\end{array}$ \\
\hline A 25-year-old mother of ane, Dasomba tribe & $\begin{array}{l}\text { "I experienced increased appetite after three } \\
\text { months of my pregnancy. I ate so heavy that I put } \\
\text { on weight and I was advised to check my weight". }\end{array}$ \\
\hline
\end{tabular}

It was observed that there were ethnic differences on what is prohibited/not recommended during pregnancy. There was however a general agreement that too much sugar and salt was bad for pregnancy.

\section{Perceived Functions of Food by Pregnant Women}

The majority of the women interviewed associated the foods to three dominant functions (foods that make foetus grow, give energy and good health). Cereals and legumes were largely considered "to help with fetal growth", "give energy" or "give good health." Some foods, such as green leafy vegetables consumed as stews or soups - were believed to "give good health" as well.

For example, a 36 year old Gonja woman indicated that she consumed "Tuo Zafi"(A traditional Northern Ghana staple prepared from millet/maize and cassava flour) with green leafy vegetables during pregnancy because it makes her baby healthy.

Foods such as eggs, watermelon, pineapple, fish, meat and baobab leaves were seen to give blood and make the foetus healthy. A 25-year-old Mampursi woman also stated that she consumes eggs, watermelons, pineapple and fish with baobab leaves soup because she hears that they give blood and make babies healthy (Table 4).

Clay/rock, ice block and biscuit and kulikuli (groundnut paste cake) were believed to minimize nausea and vomiting (Table 3). They did not mention specific nutrients and the role they play in the body. 


\begin{tabular}{|c|c|c|}
\hline Perceived functions & Foods & Nutritional function ${ }^{*}$ \\
\hline $\begin{array}{l}\text { These foods were generally } \\
\text { perceived to make the mother } \\
\text { healthy and make the foetus } \\
\text { grow. }\end{array}$ & $\begin{array}{l}\text { beans, Bambara beans, banana, } \\
\text { doreqdasa }\end{array}$ & $\begin{array}{l}\text { Provide protein, B vitamins, } \\
\text { energy and some iron }\end{array}$ \\
\hline Give strength (energy) & bananas, kerbe, tua zafo, tica & $\begin{array}{l}\text { Provide energy, some } \\
\text { protein, B vitamins and } \\
\text { some iron }\end{array}$ \\
\hline Give good health & $\begin{array}{l}\text { orange, vegetables, okra, eggs } \\
\text { and aleefu, soft drink, malt, } \\
\text { vegetables, fish, Duka drink, } \\
\text { cheese }\end{array}$ & $\begin{array}{l}\text { Provide protein, vitamin C, } \\
\text { iron, Calcium }\end{array}$ \\
\hline $\begin{array}{l}\text { Gives the pregnant woman blood } \\
\text { and makes foetus healthy }\end{array}$ & $\begin{array}{l}\text { egg, watermelon, leaves } \\
\text { pineapple, fish, meat, baobab }\end{array}$ & $\begin{array}{l}\text { Provide protein, iron, } \\
\text { calcium, Vitamins A and B }\end{array}$ \\
\hline Minimises nausea and vomiting & $\begin{array}{l}\text { clay/rock, ice and biscuit, } \\
\text { kublibuli. }\end{array}$ & \\
\hline $\begin{array}{l}\text { Foods with unspecified } \\
\text { functions }\end{array}$ & $\begin{array}{l}\text { yorowerse porridge, koase, } \\
\text { bulloult, gari and yam, palm nut }\end{array}$ & $\begin{array}{l}\text { Provide protein, energy, } \\
\text { vitamins and } A \text { and iron }\end{array}$ \\
\hline
\end{tabular}

For some traditional foods, which some of the women mentioned such as yoroyoro (maize boiled and eaten with oil and paper), porridge (a breakfast made from cereals), koose (pancake made from beans or Bambara beans), gari (local dish made from cassava), yam and palm nut soup, the women did not specify their functions. For a summary of the foods and their functions see Table 3.

\section{Sources of Knowledge on Pregnancy Food}

During the interview the women were asked about the sources of knowledge on pregnancy recommended and prohibited foods. The results show that the women drew their knowledge on pregnancy foods from the following sources:

1. Family and friends

2. Schools

3. Health systems: doctors and nurses

4. Media: radio and televisions

5. Experience from previous pregnancies

Almost all the women mentioned family and friends as a primary source of knowledge for pregnancy recommended and prohibited foods. A majority also mentioned media and health professionals as sources of knowledge. All women with more than one child said they learned about the foods they could or could not eat during pregnancy from experiences with previous pregnancies.

\section{Factors Mediating Food Practices During Pregnancy}

The women also indicated they experienced some physiological changes during pregnancy. These changes include increased sensitivity to smell, light and motion (hypersensitivity and hyperemesis), which according to them mostly occurred in the first three to four months of the pregnancy.

\section{Hypersensitivity to smell}

Hypersensitivity to smell was attributed to nausea, vomiting and spiting. This was largely considered the most important factor that could modify respondent's dietary habits during the first three months of pregnancy, especially those who experienced hypersensitivity. For example, a 32-year-old Dagomba woman explained that she could not eat anything with eggs, fish, meat or onions but could only eat fried or dried foods during the first three months of her pregnancy (Table 4). This according to others could happen throughout the entire period of pregnancy. For instance, a 30-year-old Hausa woman observed that she could not eat anything containing eggs, meat or fish when she was pregnant because she vomits after and could only take drinks and dried foods/fried yam. Therefore, women who experienced this had their diet greatly restrained. 


\section{Increased appetite and food craving}

Some of the participants also reported episodes of increased appetite and craving out-of-ordinary foods mostly between $5^{\text {th }}$ and $7^{\text {th }}$ month of the pregnancy. Others indicated that they experienced it throughout the entire period of pregnancy. According to these women, during this period they had an excessive appetite and ate several times a day. For instance, a 25-year-old woman explained that she experienced an increased appetite after the first trimester of her pregnancy and ate so heavy that she put on weight (Table 4).

A significant number of the respondents who experienced excessive appetite reported that they craved out-of-ordinary foods and the most common items craved for were clay/rocks, ice cream/block, soda/soft drinks and biscuits.

Overall, the physiological changes during pregnancy were the most important experience described by the women, which could have a profound effect on their food behavior and consumption. As women who experienced hypersensitivity and increased appetite would change their dietary behaviors in order to mitigate the effects of these feelings during pregnancy.

\section{DISCUSSION}

An inability of pregnant women to comply with expert nutrition advice during pregnancy is usually attributed to limited access to expert nutrition knowledge or cultural beliefs and practices. This study highlights the overarching factors that influence food beliefs and practices during pregnancy and by extension the consumption or non-consumption of certain foods during pregnancy. Three key elements emerge from this study: (1) Women obtain their knowledge on food from three sources (indigenous-from family members and friends, mass media and health professionals) to make sense of pregnancy and pregnancy diets; (2) the knowledge they obtained from family and friends, mass media and that from health professionals (expert nutrition knowledge) have some elements in common, among them specific recommended and prohibited foods. It is important to state that this food list represents the foods as they are perceived by the women - foods which are either craved, consumed or both during pregnancy but may not be largely recommended. The foods that were listed as recommended were generally plant-based, made either from maize, rice, millet, cassava, vegetables, some fruits, fish and meat. The prohibited foods listed by the participants included mango, gari (local dish made from cassava), banana, hot paper and groundnut soup; and (3) The physiological changes that occur during pregnancy were considered a significant modifier of dietary practices during pregnancy.

Of note, expectant mothers were restricted from eating eggs and fish; it was believed to cause the unborn baby to develop bad habit or steal during later life. ${ }^{17,25}$ Also any intake of honey was discouraged because it was thought to plug the birth canal..26,20, However, many of these beliefs have been transformed and evolved over time - "modern" medicine seems to be a reliable option for women, as well. Biomedical information and knowledge are now also available to traditional, religious, and modern caregivers and also the mothers themselves. ${ }^{26}$ As evidenced in this study, women now consumed eggs and fish during pregnancy as a result of education and counseling they receive in antenatal clinics as well as mass media. Implying that investing more in nutrition education and counseling in antenatal care clinics could help eliminate traditional cultural practices and beliefs that adversely affect pregnancy nutrition. The consumption of fried food, soft drinks, ice-cream, and biscuits as indicated by some of the mothers in this study also showed contemporary nutrition items known to have a negative effect on health. ${ }^{27,28,29,30,31}$ Here, adverts on televisions and radios most likely are the culprit. This implies that more education and counseling during ANC is still required to counter the adverts in the mass media and the remaining cultural practices that undermine optimal nutrition during pregnancy.

Several studies conducted in Ghana and elsewhere on recommended and prohibited foods made similar observations as with the present study. For example, one study conducted in Accra, Ghana observed that some pregnant women avoid fufu, gari, kokonte (all cassava based foods), fresh fish, corn 
dough porridge, eggs, banana, crabs and ripe plantain. ${ }^{32}$, Another study conducted in the Western region showed that pregnant women avoided mango, gari and high sugar beverages (malt and Milo) and sweet potatoes. ${ }^{20}$ Foods - as well as beliefs and practices related to it - are ethnically bound, so that foods specific to certain groups and regions of Ghana appear to be held onto by women originally from these regions, no matter how long they had lived outside those regions. ${ }^{7}$

Largely the functions attributed to traditional foods by the participants were similar to that of the biological functions of the foods although they were more general in understanding. The functions of foods perceived by the pregnant women, to a large extent, corresponded to the actual nutritional functions of the foods ${ }^{33}$ (expert nutrition knowledge). Four main functional categories were given to recommended traditional foods. Of these, three categories corresponded to the actual nutritional functions (expert nutrition knowledge): (1) Foods that prevented anemia (e.g., dark green leafy vegetables, eggs, fish and watermelon), (2) Makes the fetus grow (e.g., fish, meat, dawadawa, fruits and vegetables), (3) Provided general health enhancing functions (e.g. beans, vegetables, and fruit) and gives energy (e.g. banana and cereal based meals). The other category did not have clear nutritional functions: foods that minimized physiological disruption or 'morning sickness' (clay, biscuit and kulikuli). Identification of legitimation processes showed that women subjected all sources of pregnancy information to scrutiny. Thus, elements of both (indigenous nutrition knowledge) and expert nutrition knowledge that had proven functions were considered.

The most common sources of foods recommended and prohibited foods during pregnancy identified in this study include family and friends, mass media and health professionals. This observation is consistent with other studies, which found mass media, ${ }^{24}$ health professionals and family and friends ${ }^{7}$ as common sources of health and nutrition information. Surprisingly, none of the respondents mentioned traditional birth attendant as a source of knowledge of pregnancy recommended or prohibited foods. Perhaps this is due to the increased coverage of antenatal care in Ghana, which might have rendered the traditional birth attendance redundant. Processes of adoption of pregnancy knowledge are largely depended on the culture and unique pregnancy experiences. ${ }^{7}$

Physiological changes during pregnancy had a profound effect on respondents' food behavior and consumption and overruled the knowledge they had (e.g. from family and friends, mass media, or health professionals). For example, respondents indicated they consumed fried food in order to manage nausea and vomiting during pregnancy. Ice cream, soda drinks, and biscuits were also reported to be craved for. However, these food items have been shown to increase the risk for gestational diabetes, overweight or obesity, and other negative outcomes. $27,28,29,34,35,36$ Physiological changes during pregnancy could enhance appetite for healthy foods positively, but extreme physiological changes could cause either under consumption or overconsumption of nutritious or non-nutritious foods. For many women the pregnant body (and the physiological changes that come with pregnancy) is the most important factor that influences how the women think, feel, and act about food daily during pregnancy, and might override other legitimate sources of knowledge (e.g. structural, cultural) on the right or wrong of pregnancy foods. ${ }^{7}$

This has implications for nutrition counseling during antenatal clinics in Northern Ghana and the nation as a whole. Pregnant women should be assisted and supported in an appropriate way to minimize consumption of foods that can be detrimental to the health of the mother and the fetus.

\section{Ethical Aspects}

The mothers were informed about the study and asked to sign a written consent form. For those who could not read and write, this was done through an interpreter (someone who was not part of the study). The Ethics committees of Navrongo Health Research Centre (Ref. No: App/MatNut/01/2014) and University of Heidelberg approved the study. The study took place between February and August 2014.

\section{CONCLUSION}

The study shows that both indigenous and expert nutrition knowledge as well as previous pregnancy experience are important modifiers of food practices during pregnancy. However, the most important 
factor might be the physiological changes that take place during pregnancy for most pregnant women. These changes have implications for nutrition counseling during antenatal clinics as this could lead to excessive appetite or loss of appetite. Women whose experiences lie at both end of the physiological disruption are more likely unable to follow nutritional counselling or advice during ANC and therefore require individualized counseling. The difficulty lies in designing cost-effective and practical interventions that enable already over-stretched and resource limited maternal health services in Ghana to provide individualized nutrition counseling. However, this is crucial since eating appropriately during pregnancy is essential for the future health of the unborn child and the mother.

\section{LIST OF ABBREVIATIONS}

ANC: Antenatal care

FAO: Food and Agricultural Organization

\section{ACKNOWLEDGMENTS}

We express our gratitude to all the managers of the Hospitals where the data collection took place especially the Head of the Obstetrics and Gynecology Department of TTH and all the midwives in charge of the labor and maternity wards of TTH, TCH, TWH, and SDH. We also thank the nutrition officers of the above hospitals for their immense support during the data collection. This work would not have been possible without the support of the Dean of School of Medicine and Health Sciences, University for Development Studies, Tamale, Ghana.

\section{FUNDING}

Authors received no external funding for this research.

\section{NOTES}

We have no competing interest to declare.

The first author conceived and designed the study. He also performed the data analysis and interpretation, with the help of the last author. The first author wrote the first draft of the manuscript with the second and third authors contributing to finalizing the manuscript.

\section{REFERENCES}

1. Christian, P. 2010. "Micronutrients, birth weight, and survival." Annu Rev Nutr 30:83-104. doi: 10.1146/annurev.nutr.012809.104813.

2. Haider, B. A., Yakoob, M. Y. and Bhutta, Z. A. 2011. "Effect of multiple micronutrient supplementation during pregnancy on maternal and birth outcomes." BMC Public Health 11 Suppl 3:S19. doi: 10.1186/1471-2458-11-s3-s19.

3. Popkin, Barry M. 2005. "Using research on the obesity pandemic as a guide to a unified vision of nutrition." Public Health Nutrition 8:724-29.

4. Müller O., and Jahn A. 2009. "Malnutrition and Maternal and Child Health." In Maternal and Child Health, edited by Ehiri J, 287-310. NewYork, Dordrecht, Heielberg, London: Springer.

5. de-Graft Aikins, A. 2011. "Culture, diet and the maternal body: Ghanaian women's perspectives on food, fat and childbearing." In Fatness and the Maternal Body: Women's experiences of corporeality and the shaping of social policy, edited by Soraya Tremayne, 130-154. Oxford: Berghahn Books.

6. de-Graft Aikins, A. 2014. "Food beliefs and practices during pregnancy in Ghana: implications for maternal health interventions." Health Care Women Int 35 (7-9):954-72. doi: 10.1080/07399332.2014.926902.

7. Kumari AS. 2001. Pregnancy outcome in women with morbid obesity. International Journal of Gynecology \& Obstetrics 78.

8. GSS/GHS/ICF Macro. 2009. Ghana Demographic and Health Survey 2008. Accra, Ghana.

9. Addo, A. A., Marquis, G. S., \& Lartey, A. A. 2006. "Dietary intakes of Ghanaian pregnant and lactating women living in HIV affected communities." Africa Nutrition Epidemiology, Accra, Ghana, 15-18 August.

10. Quarshie, K., Amoaful, E., \& Armah, J. G. A. 2006. " Communications strategy for the control of malnutrition in Ghana." Africa Nutrition Epidemiology, Accra, Ghana, 15-18 August.

11. Rozin, Paul. 1990. Social and Moral Aspects of Food and Eating, The Legacy of Solomon Asch: Essays in Cognition and Social Psychology. New York: Psyhcology Press.

12. Rifas-Shiman, S. L., Rich-Edwards, J. W., Kleinman, K. P., E. Oken, and M. W. Gillman. 2009. "Dietary quality during pregnancy varies by maternal characteristics in Project Viva: a US cohort." J Am Diet Assoc 109 (6):1004-11. doi: 10.1016/j.jada.2009.03.001. 
13. Oni, O. A., and J. Tukur. 2012. "Identifying pregnant women who would adhere to food taboos in a rural community: a community-based study." Afr J Reprod Health 16 (3):68-76.

14. Egwuatu, V. E. 1986. "Childbearing among the Igbos of Nigeria." Int J Gynaecol Obstet 24 (2):103-9.

15. Boyacioglu, A. O., and Turkmen, A. 2008. "Social and cultural dimensions of pregnancy and childbirth in eastern Turkey." Cult Health Sex 10 (3):277-85. doi: 10.1080/13691050701673925.

16. Meyer-Rochow, V. B. 2009. "Food taboos: their origins and purposes." J Ethnobiol Ethnomed 5:18. doi: 10.1186/17464269-5-18.

17. Santos-Torres, M. I., and Vasquez-Garibay, E.. 2003. "Food taboos among nursing mothers of Mexico." J Health Popul Nutr 21 (2):142-9.

18. Hartini, T. N., Padmawati, R. Lindholm, S. Surjono, L. A. and Winkvist, A. 2005. "The importance of eating rice: changing food habits among pregnant Indonesian women during the economic crisis." Soc Sci Med 61 (1):199-210. doi: 10.1016/j.socscimed.2004.11.043.

19. Otoo, Patience, Helen Habib, and Augustine Ankomah. 2015. "Food Prohibitions and Other Traditional Practices in Pregnancy: A Qualitative Study in Western Region of Ghana." Advances in Reproductive Sciences 03 (03):41-49. doi: 10.4236/arsci.2015.33005.

20. Horrobin, D. F. 1982. "In praise of non-experts : Horrobin, David, 1982. New Scient., 94(1311):842-844." Deep Sea Research Part B. Oceanographic Literature Review 29 (12):810. doi: http://dx.doi.org/10.1016/0198-0254(82)90454-X.

21. Erren, T. C., Koch, M. S. and Meyer-Rochow V. B. 2013. "Common sense: folk wisdom that ethnobiological and ethnomedical research cannot afford to ignore." J Ethnobiol Ethnomed 9:80. doi: 10.1186/1746-4269-9-80.

22. Albert Einstein quotes: http://www.inspirational-motivational-success quotes.com/alberteinsteinquotes.html

23. Ghana Statistical Service. 2010. Population and housing census. Accra, Ghana: Ghana statistical service.

24. Lawrence A, Palinkas, Sarah M. Horwitz, Carla A. Green, Jennifer P. Wisdom, Naihua Duan, Kimberly Hoagwood 2015. Purposeful sampling for qualitative data collection and analysis in mixed method implementation Research, 533-544

25. Ogbeide, O. 1974. "Nutritional hazards of food taboos and preferences in Mid-West Nigeria." Am J Clin Nutr 27 (2):2136.

26. Fischer, Michelle. 2002. "Childbearing in Ghana: How beliefs affect care."

27. Bao, W., Tobias, D. K., Olsen, S. F. and Zhang, C.. 2014. "Pre-pregnancy fried food consumption and the risk of gestational diabetes mellitus: a prospective cohort study." Diabetologia 57 (12):2485-91. doi: 10.1007/s00125-014-3382-x.

28. Sayon-Orea, C., M. Bes-Rastrollo, F. J. Basterra-Gortari, J. J. Beunza, P. Guallar-Castillon, C. de la Fuente-Arrillaga, and M. A. Martinez-Gonzalez. 2013. "Consumption of fried foods and weight gain in a Mediterranean cohort: the SUN project." Nutr Metab Cardiovasc Dis 23 (2):144-50. doi: 10.1016/j.numecd.2011.03.014.

29. Guallar-Castillon, P., Rodriguez-Artalejo, F. Fornes, N. S. Banegas, J. R. Etxezarreta, P. Ardanaz, A. E. Barricarte, A. Chirlaque, M. D. Iraeta, M. D. Larranaga, N. L. Losada, A. Mendez, M. Martinez, C. Quiros, J. R. Navarro, C. Jakszyn, P. Sanchez, M. J. Tormo, M. J. and Gonzalez, C. A. 2007. "Intake of fried foods is associated with obesity in the cohort of Spanish adults from the European Prospective Investigation into Cancer and Nutrition." Am J Clin Nutr 86 (1):198-205.

30. Cahill, L. E., Pan, A., Chiuve, S. E., Sun, Q., Willett, W. C., Hu, F. B. and E. B. Rimm. 2014. "Fried-food consumption and risk of type 2 diabetes and coronary artery disease: a prospective study in 2 cohorts of US women and men." $A m J$ Clin Nutr 100 (2):667-75. doi: 10.3945/ajcn.114.084129.

31. Cuco, G., Fernandez-Ballart, J., Sala, J., Viladrich, C., Iranzo, R., VILA, J. \& Arija, V. 2005. Dietary patterns and associated lifestyles in preconception, pregnancy and postpartum. Eur J Clin Nutr, 60, 364-371.

32. Nti, Christina A., Patience M. Larweh, and Yaa Gyemfua-Yeboah. 2002. "Food consumption patterns, dietary quality and health status of expectant mothers: case studies in suburban and rural communities in Ghana." International Journal of Consumer Studies 26 (1):7-14. doi: 10.1046/j.1470-6431.2002.00211.x.

33. FAO. 2012. West African Food Composition Table. Rome: FAO.

34. Claudia Beiersmann, Manuela De Allegri, Mamadou Sanon, Justin Tiendrebeogo, Albrecht Jahn1 and Olaf Mueller. 2008. "Community Perceptions on Different Delivery Mechanisms for Insecticide- Treated Bed Nets in Rural Burkina Faso." Public Health Journal, 1:17-24.

35. Callahan, Gerald N. 2003. "Eating dirt." Emerging Infectious Diseses 9 (8):1016-1021.

36. Chijioke, I., G. Ilechukwu, G. Ilechukwu, C. Okafor, I. Ekejindu, and M. Sridhar. 2011. "A community based survey of the burden of ascaris lumbricoides in enugu." Ann Med Health Sci Res 1 (2):165-71. 